\title{
Competitive Biomass Allocation Between the Main Shoot and Lateral Branches of Broccoli (Brassica oleracea L. var. italica)
}

\author{
Megumu Takahashi and Hidekazu Sasaki*
}

Institute of Vegetable and Floriculture Science, NARO, Tsukuba 305-8519, Japan

The branching habit and stalk proportion of heading type broccoli (Brassica oleracea L. var. italica) differs based on the cultivar, but the extent of the effects of these factors on the apical head weight is unknown. The main objectives of this study were to elucidate the relationships between the apical head weight and the branching habit or the stalk proportion. Firstly, the shoots of broccoli from six cultivars were divided into four parts (apical head, leaves on the main stem, lateral branches, and the rest of the main stem), and the weight proportions of each part were investigated. The results showed that the cultivars showing higher branching tended to produce smaller apical heads. Furthermore, apical head weights showed a positive relationship with the area of the leaves on the main stem, but a negative relationship with those on the branches. Secondly, four cultivars were grown with lateral bud nipping. This significantly increased the apical head weight in the cultivars showing higher lateral branching, but did not significantly change the weight of the whole shoot. These results suggest competitive biomass allocation between the main shoot and lateral branches. The difference in the weight of lateral branches depended on the probability of axillary bud presence rather than on the number of internodes or weight per branch. Finally, a strong correlation between the apical head weights and the square of the stalk diameter was demonstrated by generalized linear models $\left(R^{2}=0.95\right)$. These findings will contribute to the knowledge base on diverse methods of broccoli cultivation.

Key Words: apical dominance, bud development, generalized linear model, leaf area, nipping.

\section{Introduction}

Plants respond to environmental changes by distributing biomass among various plant organs to optimize vegetative growth for resource capture and reproductive growth for seed production (Bazzaz et al., 1987; McCarthy and Enquist, 2007; McConnaughay and Coleman, 1999; Poorter and Nagel, 2000). Since the biomass that can be produced by a plant is limited, allocation of biomass must be carefully modulated in response to environmental factors. In intact plants showing vigorous apical shoot growth, lateral buds are generally not essential to the life cycle; excessive branching is likely to be costly (Dun et al., 2006). Therefore, elongation of lateral buds is suppressed by apical buds, making them dormant; this phenomenon is known as apical dominance (Cline, 1991; Horvath et al., 2003). In addition, several factors such as the

Received; January 24, 2019. Accepted; March 4, 2019.

First Published Online in J-STAGE on May 10, 2019.

No conflicts of interest declared.

* Corresponding author (E-mail: hsasaki@affrc.go.jp). stage of whole plant development, the node and age of the bud, as well as endogenous (hormone and gene expression) and environmental factors (light, temperature, and photoperiod) are intricately involved in the retention of lateral bud dormancy (Beveridge et al., 2003; Dun et al., 2006; Luo et al., 2019). However, lateral buds are likely to emerge and develop under photoassimilation surplus conditions, and cease development and senesce under photoassimilation shortage conditions (Lafarge and Hammer, 2002). Meanwhile, the outgrowth of lateral buds often competes with that of the apical shoots, which affects the yield in an agricultural field setting. For example, in a previous study, overproduced tillers (branches) triggered foliar $\mathrm{N}$ deficiency and were considered one of the reasons for the lower harvest index in direct-seeded rice (Oryza sativa L.) (Schnier et al., 1990). Wheat (Triticum aestivum L.) lines containing the tiller inhibition ( in) gene, which exhibits a reduction in tillers by $40 \%$ compared to its free-tillering counterpart, produced a higher yield than all other lines studied (Duggan et al., 2005a, b). The development of a single large flower head entails nipping the axillary buds in a floricultural field setting (Adjei- 
Frimpong et al., 2011; Cockshull, 1982). The number of branches is usually restricted to increase the yields and quality of fruits and vegetables (De Swart et al., 2006; Georgiev, 1991; Maghfoer et al., 2015).

There are various methods of broccoli (Brassica oleracea L. var. italica) cultivation based on the use of lateral branches. Broccoli is roughly classified as a "sprouting" or "heading" type, depending on the degree of branching exhibited and the size of the inflorescences (Martin and Sideman, 2012). In the sprouting type, multiple smaller secondary heads are harvested instead of a single large head (Martin and Sideman, 2012; Reilly et al., 2014). In the heading type, only the apical (central) large head is usually harvested (Erdem et al., 2010; Jett et al., 1995; Tremblay, 1989), but sometimes, lateral heads (small secondary heads) are subsequently harvested, enabling an increase in total yield (Bouquet, 1950; Singh et al., 2011; Stephens, 1994; Yoldas et al., 2008). In some studies, techniques for harvesting two large heads from one plant by growing a lateral branch after the apical head harvest (Pornsuriya and Teeraskulchon, 1997; Sato, 2015; Takahashi et al., 2018a) or by pinching the apical bud and growing two lateral branches (Kodera, 1988; Takahashi et al., 2019), were examined or proposed. Each cultivar is bred and produced for a particular purpose, resulting in the development of a branching habit in each variety. It is known that a cultivar with a large apical head tends to have fewer branches empirically, while one with a small apical head tends to have more branches (Bouquet, 1950; Le Strange et al., 1996). However, the biomass trade-off between the main shoot and lateral branches has not been quantified yet. Elucidating the biomass allocation to lateral branches and the influence of lateral branches on the yield (apical head weights) will be beneficial for selecting and breeding a suitable broccoli cultivar. In addition, as we demonstrated that two large heads could be harvested by nipping extra branches (Takahashi et al., 2018a, 2019), elucidating the effect of nipping branches on head growth will also be beneficial to understanding and improving methods for more stable production.

Increased planting density was reported to reduce the apical head weight and stalk (the stem part of the head) diameter (Kahn et al., 1991). In another study, increased planting density was not reported to affect the apical head diameter, but it did reduce the apical head weight (Francescangeli et al., 2006). These studies suggest that the stalk size easily fluctuates and influences the apical head weight. It can be assumed that the differences in the apical head weights among different cultivars are caused by the difference in the stalk size. Therefore, elucidating the relationship between the apical head weight and stalk size is important, considering its effect on broccoli yield.

Therefore, in this study experiments were conducted using six cultivars to elucidate the influence of lateral branches on biomass allocation within the whole shoot, the differences in the characteristics of lateral branches among cultivars, and the relationship between the apical head weight and stalk diameter.

\section{Materials and Methods}

\section{Analysis of shoot part ratios (Exp. 1)}

The experiments were conducted at a field in NARO, Tsukuba City, Ibaraki Prefecture, Japan $\left(36^{\circ} 01^{\prime} \mathrm{N}\right.$, $140^{\circ} 06^{\prime}$ E). The soil was classified as Andisol, Typic Hapludands. The cultivars used in this study were 'Pixel', 'Ryokurei', 'Grandome' (Sakata Seed Co., Ltd., Yokohama, Japan), 'Speed Dome' (Mikado Kyowa Seed Co., Ltd., Chiba, Japan), 'Madoka' (Brolead Co., Ltd., Tsu, Japan), and 'Yumehibiki' (Nanto Seed Co., Ltd., Kashihara, Japan). Seeds were sown in cell trays $(25 \mathrm{~mL} \times 128$ cells) filled with compost (NAPLA type S; YANMAR Co., Ltd., Osaka, Japan) on 4 Jan. 2017 and grown in a greenhouse. The temperature in the greenhouse was maintained above $10^{\circ} \mathrm{C}$. Starting from two weeks after sowing, the seedlings were fertilized with $300 \mathrm{mg} \mathrm{N}, 160 \mathrm{mg} \mathrm{P}_{2} \mathrm{O}_{5}$, and $340 \mathrm{mg} \mathrm{K}_{2} \mathrm{O}$, in the form of a liquid (OAT Agrio Co., Ltd., Tokyo, Japan), per cell tray. To avoid exposing the seedlings to the severely cold climate of the field immediately, they were acclimatized to low temperatures above $1^{\circ} \mathrm{C}$ for $3-5$ days just before transplanting. The seedlings were transplanted on 15 Feb. 2017 into the study field, covered with black plastic mulch and placed in transparent low plastic tunnels (PVC film, $0.075 \mathrm{~mm}$ thickness) at a planting density of 1.6 plants $\cdot \mathrm{m}^{-2}(160 \mathrm{~cm}$ between ridges and $40 \mathrm{~cm}$ between plants). The practical density for heading type broccoli is $3.0-3.6$ plants $\cdot \mathrm{m}^{-2}$ (Jett et al., 1995; Schellenberg et al., 2009), but we set approximately half of this density to accommodate the development of branches. The field was fertilized with $\mathrm{N}, \mathrm{P}_{2} \mathrm{O}_{5}$, and $\mathrm{K}_{2} \mathrm{O}$ at rates of 4,4 , and $3 \mathrm{~kg} \cdot \mathrm{a}^{-1}$, respectively.

When apical heads reached a diameter of $12 \mathrm{~cm}$, the whole shoot was divided into four parts: the apical head, leaves on the main stem, lateral branches, and the rest of the main stem. Then, the fresh weight (FW) of each part was measured. The stalk of the apical head was trimmed at $15 \mathrm{~cm}$ from the top of the dome to give a cut-off section based on the typical standard in Japan (Kodera, 1988). Leafstalks on the apical head were trimmed within the width of the head diameter (cf. Takahashi et al., 2018a). The diameter of the cut-off section was measured as the stalk diameter. Both axillary branches (originating from leaf axils) and adventitious branches (originating from the boundary part between the main stem and roots) were regarded as lateral branches as long as the thickness of the basal part was more than $5 \mathrm{~mm}$. Leaf area (LA) including leafstalks was measured using an area meter (LI-3100; Meiwafosis Co., Ltd., Tokyo, Japan). Hereafter, the sum of LA of the leaves on the main stem is expressed as 
$\mathrm{LA}_{\mathrm{M}}$, that of the lateral branches as $\mathrm{LA}_{\mathrm{B}}$, and the sum of $\mathrm{LA}_{\mathrm{M}}$ and $\mathrm{LA}_{\mathrm{B}}$ (LA of the whole shoot) as $\mathrm{LA}_{\mathrm{W}}$. Six plants of each cultivar were included per replicate; three replicates were studied. Three plants of each cultivar were dried at $80^{\circ} \mathrm{C}$ for one week, and dry matter was weighed. The dry matter concentration (\%) of each part of each cultivar was calculated by dividing dry matter weights by FW.

\section{Nipping lateral buds (Exp. 2)}

The cultivars used in this experiment were 'Pixel', 'Ryokurei', 'Speed Dome', and 'Yumehibiki'. Their seeds were sown on 14 Feb. 2018 and they were transplanted on 9 March 2018. The conditions for seedling nursing and cultivation were the same as those in Exp. 1 except for the plant density, which was maintained at 3.2 plants $\cdot \mathrm{m}^{-2}(160 \mathrm{~cm}$ between ridges, $60 \mathrm{~cm}$ between two columns of plants in one ridge, and $40 \mathrm{~cm}$ between plants). In nipping plots, lateral buds were removed as soon as they were generated. When apical heads reached a diameter of $12 \mathrm{~cm}$, the whole shoot was divided and weighed as in Exp. 1. In both control and nipping plots, three plants of each cultivar were included per replicate; three replicates were studied.

\section{Comparison of lateral branches among cultivars (Exp. 3)}

The number of internodes $(N I)$ from the first internode directly under the first true leaf, to the last one directly under the first floret of the apical head, was counted for the plants in Exp. 1. The probability of axillary bud presence $(P A)$ was derived by dividing the number of axillary buds per plant by the respective $N I$. We collected lateral branches with basal part thickness of more than $5 \mathrm{~mm}$, and measured their FW, LA, basal part thickness, and length and diameter of the lateral head. The FW of one lateral branch is expressed as $W B$.

\section{Analysis of the relationship between apical head weight and stalk diameter}

The relationship between the FW of apical heads and stalk diameters obtained in Exp. 1 was examined using generalized linear models (GLM) (Crawley, 2005; Takahashi et al., 2018b). FW values of apical heads and stalk diameters were represented as $A$ and $S$, respectively, in GLM and equations. Assuming that the observed variation in $A$ follows a Gaussian distribution with a mean of $A_{i}$ and standard deviation of $\sigma_{i}$, we set $S$ as the explanatory variable in the linear predictor. Subsequently, the below log link function was applied:

$$
\ln (A)=\beta_{0}+\beta_{1} S+\beta_{2} S^{2} .
$$

The parameters in the above equation $\left(\beta_{0}, \beta_{1}\right.$, and $\left.\beta_{2}\right)$ and Akaike's information criterion (AIC) value were estimated based on the following three patterns: including both terms of the first and second degree (Eq. \#1), including only the term of the first degree (Eq. \#2), and including only the term of the second degree (Eq. \#3), using the ' $\mathrm{glm}$ ' function of the R software package ( $\mathrm{R}$ Core Team, http://www.R-project.org., 2015). The resulting equations were then expressed in the following form:

$$
\begin{aligned}
& \text { Eq.\#1: } A=\exp \left(\beta_{0}+\beta_{1} S+\beta_{2} S^{2}\right) \\
& \text { Eq.\#2: } A=\exp \left(\beta_{0}+\beta_{1} S\right) \\
& \text { Eq. \#3: } A=\exp \left(\beta_{0}+\beta_{2} S^{2}\right) .
\end{aligned}
$$

Finally, we confirmed the best model according to the significances of explanatory variables, the coefficient of determination $\left(R^{2}\right)$, and the AIC value.

\section{Statistical analysis}

Statistical analysis was performed using $\mathrm{R}$ software. Multiple tests for proportion data (dry matter concentration and $P A$ ) were performed after inverse sine transformation.

\section{Results}

Analysis of shoot part ratios (Exp. 1)

Each cultivar needed 68-76 days after transplanting to reach the standard size for harvest (Table 1). The FW of apical heads varied depending on the cultivar; the cultivars are arranged from left to right in Figure 1 in decreasing order of apical head FWs. The highest proportion of apical head within the shoot was $31.4 \%$ in 'Madoka' (Fig. 2a). The proportions of apical heads were approximately $25 \%$ in 'Grandome', 'Yumehibiki', 'Pixel', and 'Speed dome'. The lowest proportion of apical heads was $17.2 \%$ in 'Ryokurei'.

The proportion of leaves on the main stem was significantly higher in 'Madoka' $(62.2 \%)$ and 'Grandome' $(66.6 \%)$, than that in other cultivars (Fig. 2a). However, the lowest proportion of leaves on the main stem was $26.6 \%$ in 'Ryokurei'.

There were no lateral branches in 'Madoka' (Fig. 1). It was difficult to classify the lateral branches of

Table 1. Average days required by each cultivar after transplantation to bear an apical head reaching a diameter of $12 \mathrm{~cm}$, and fresh weight of the apical head.

\begin{tabular}{lrrrrrr}
\hline \hline \multicolumn{1}{c}{ Cultivar } & Madoka & Grandome & Yumehibiki & \multicolumn{1}{c}{ Pixel } & Speed dome & Ryokurei \\
\hline Days after transplanting (d) & $75 \pm 0.6^{z}$ & $76 \pm 0.3$ & $71 \pm 0.5$ & $68 \pm 0.7$ & $70 \pm 0.3$ & $73 \pm 0.6$ \\
Fresh weight of apical head (g) & $515.7 \pm 3.7$ & $457.6 \pm 3.1$ & $381.0 \pm 8.0$ & $342.1 \pm 9.3$ & $334.3 \pm 3.5$ & $281.3 \pm 6.0$ \\
\hline
\end{tabular}

${ }^{\mathrm{z}}$ Mean value $\pm \operatorname{SE}(\mathrm{n}=3)$. 


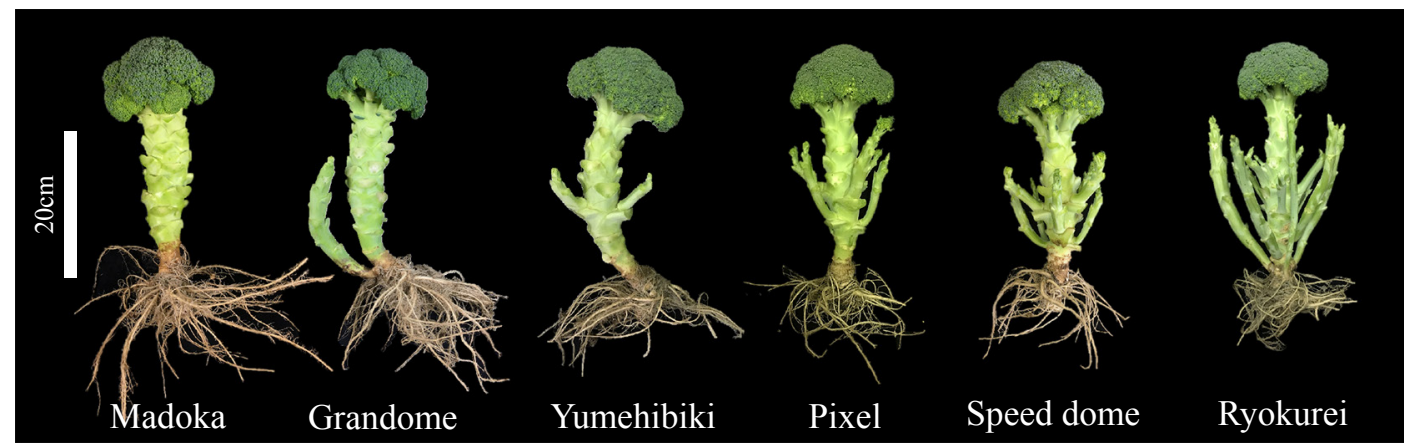

Fig. 1. Appearances of cultivars used in this study. Leaves were removed for easy recognition of the shapes. As plants were pulled out in a random manner, the roots in the picture do not reflect the whole roots.
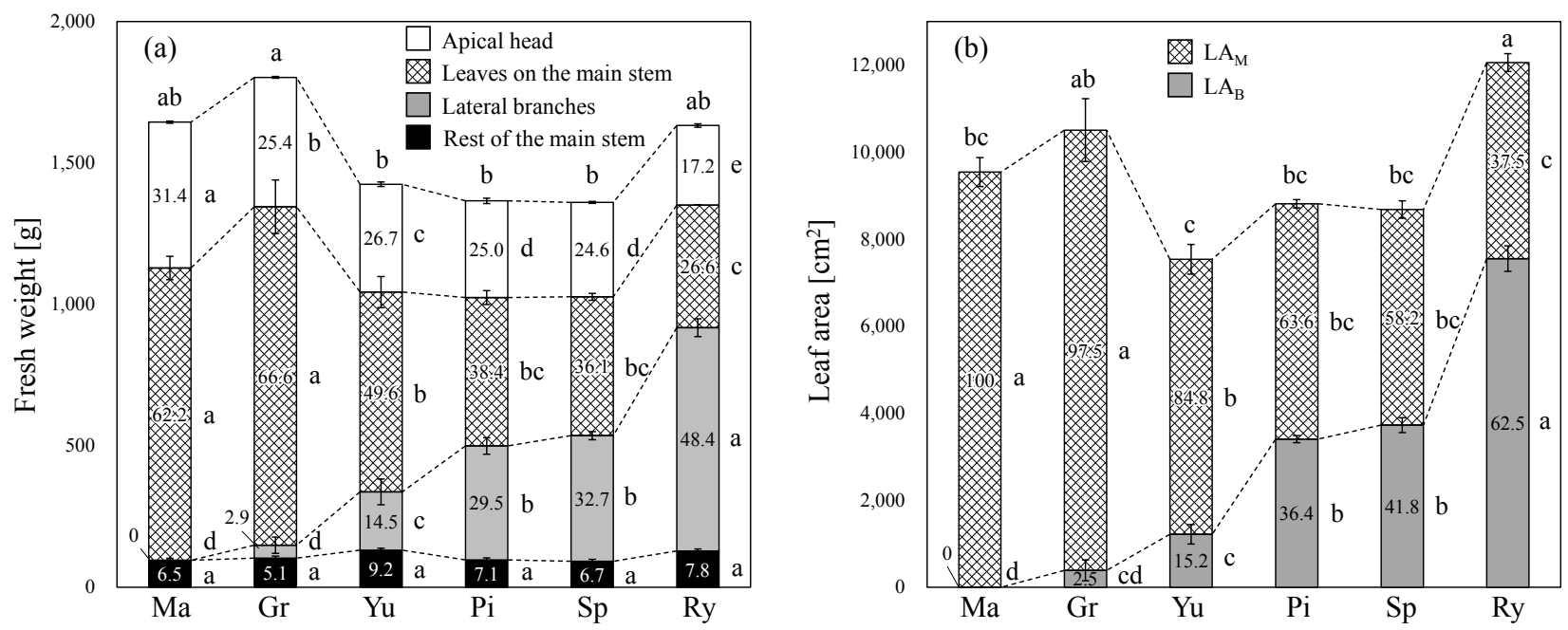

Fig. 2. (a) Fresh weights and (b) leaf areas of each part according to the cultivar. Ma, Gr, Yu, Pi, Sp, and Ry indicate 'Madoka', 'Grandome', 'Yumehibiki', 'Pixel', 'Speed dome', and 'Ryokurei', respectively. $\mathrm{LA}_{\mathrm{M}}$ and $\mathrm{LA}_{\mathrm{B}}$ indicate the leaf areas of leaves on the main stem and lateral branches, respectively. The values in bars indicate the proportions (\%) of the part within the whole shoots or leaf areas. TukeyKramer's test was performed based on the values of fresh weights or leaf areas, and the same letters within the same parts indicate nonsignificant differences at $P<0.05$. Error bars indicate SE ( $\mathrm{n}=3$ ).

'Grandome' as axillary or adventitious buds. They seemed to be adventitious buds because they grew from the boundary part between the stem and roots (Fig. 1), but they were robust and few for adventitious buds. They could be axillary buds from the low-order leaf axils buried in the soil by ridging. In either case, only $22.2 \%$ of the plants showed lateral branches, resulting in a very low lateral branch proportion $(2.9 \%)$ in 'Grandome' (Fig. 2a). The rest of the cultivars had a certain amount of lateral branches, all of which originated from axillary buds (Fig. 1); the proportions of the lateral branches were $14.5 \%$ in 'Yumehibiki', $29.5 \%$ in 'Pixel', 32.7\% in 'Speed dome', and $48.4 \%$ in 'Ryokurei' (Fig. 2a).

There were no significant differences in the remaining parts of the main stem among cultivars; their proportions ranged between $5.1-9.2 \%$ (Fig. 2a). Additionally, there were no significant differences in dry matter concentrations, all of which were approximately $9 \%$, regardless of the part or cultivar (Table S1).
The plant ratios of $\mathrm{LA}_{M}$ and $\mathrm{LA}_{\mathrm{B}}$ are shown in Figure $2 \mathrm{~b}$. The FW of the whole shoot showed a positive relationship with $\mathrm{LA}_{\mathrm{W}}$, while the $\mathrm{FW}$ of the apical head showed a positive relationship with $\mathrm{LA}_{\mathrm{M}}$ and a negative relationship with $\mathrm{LA}_{\mathrm{B}}$. The $\mathrm{FW}$ of lateral branches was the opposite of the above results at $r>0.7$ of correlation coefficients and $P<0.001$ level of significance for regression coefficients (Table 2).

\section{Nipping lateral buds (Exp. 2)}

Nipping lateral branches did not significantly change the FW of the whole shoot in any cultivar (Fig. 3). In 'Yumehibiki' and 'Pixel', nipping did not significantly change the FW of the apical head, leaves on the main stem or the rest of stem (Fig. 3a, b). Meanwhile, nipping significantly increased the FW of leaves on the main stem of 'Speed dome' and the FW of the apical head and leaves on the main stem of 'Ryokurei' (Fig. 3c, d). 
Table 2. Regression coefficients and correlation coefficients $(r)$ of the fresh weights of each part based on leaf areas.

\begin{tabular}{|c|c|c|c|c|c|}
\hline Factor & Whole shoot & Apical head & Leaves on the main stem & Lateral branches & Rest of the main stem \\
\hline \multirow{2}{*}{$\mathrm{LA}_{\mathrm{W}}^{\mathrm{z}}$} & $0.086^{* * * y}$ & $-0.007^{\mathrm{NS}}$ & $0.021^{\mathrm{NS}}$ & $0.069^{\mathrm{NS}}$ & $0.002^{\mathrm{NS}}$ \\
\hline & $r=0.73$ & $r=-0.14$ & $r=0.11$ & $r=0.40$ & $r=0.15$ \\
\hline \multirow{2}{*}{$\mathrm{LA}_{\mathrm{M}}$} & $0.058^{* *}$ & $0.032 * * *$ & $0.129 * * *$ & $-0.102^{* * *}$ & $-0.002^{\mathrm{NS}}$ \\
\hline & $r=0.71$ & $r=0.92$ & $r=0.99$ & $r=-0.85$ & $r=-0.22$ \\
\hline \multirow{2}{*}{$\mathrm{LA}_{\mathrm{B}}$} & $-0.013^{\mathrm{NS}}$ & $-0.027^{* * *}$ & $-0.091 * * *$ & $0.104 * * *$ & $0.002^{\mathrm{NS}}$ \\
\hline & $r=-0.18$ & $r=-0.89$ & $r=-0.80$ & $r=0.99$ & $r=0.28$ \\
\hline
\end{tabular}

${ }^{\mathrm{z}} \mathrm{LA}_{\mathrm{W}}, \mathrm{LA}_{\mathrm{M}}$, and $\mathrm{LA}_{\mathrm{B}}$ correspond to the means of the leaf area of the leaves on the whole shoot, main shoot, and lateral branches, respectively. y ***, **, and * indicate statistical significance at $P<0.001, P<0.01$, and $P<0.05$, respectively, and NS indicates non-significance.

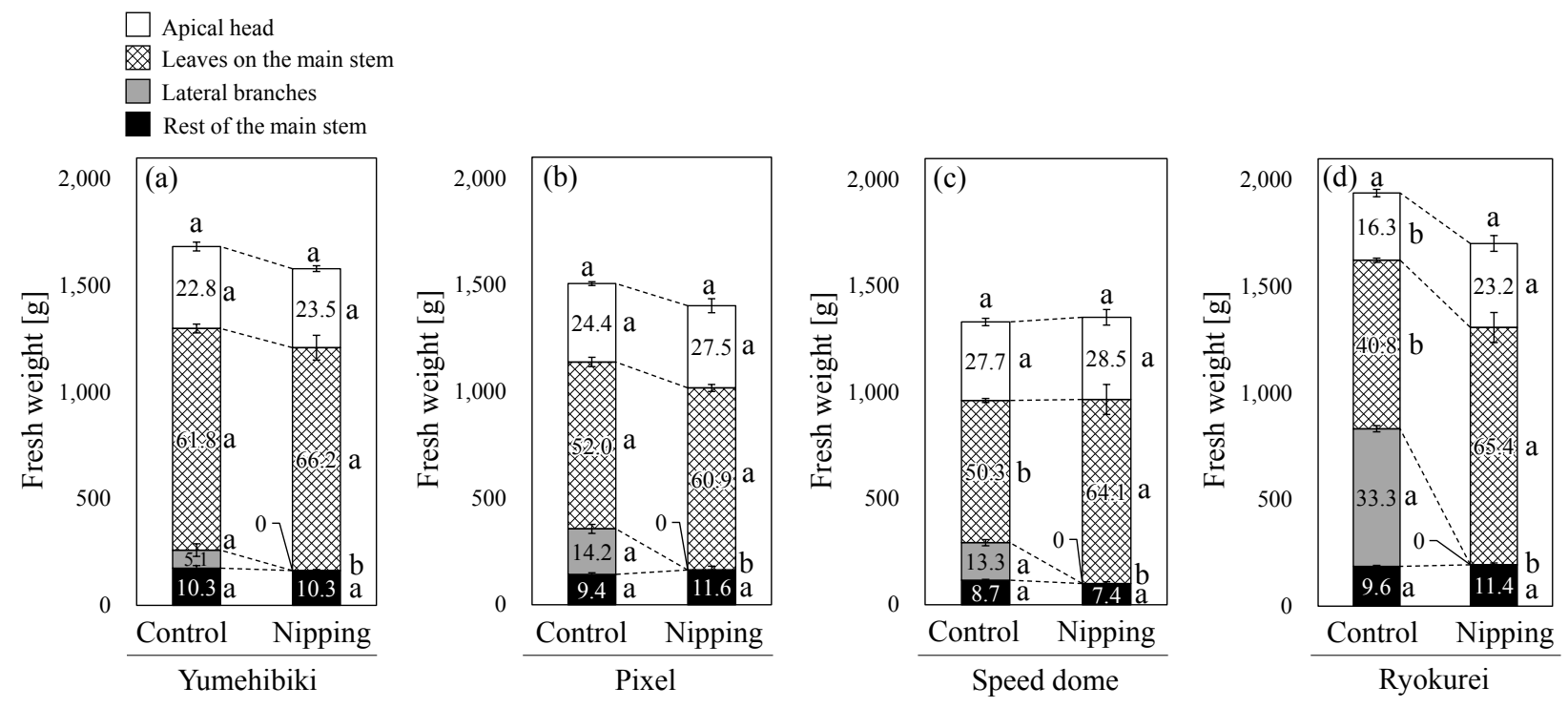

Fig. 3. Fresh weights of each part of each cultivar; (a) 'Yumehibiki', (b) 'Pixel', (c) 'Speed dome', and (d) 'Ryokurei'. The values in bars indicate the fresh weight proportions (\%) of the parts within the whole shoots. The same letters within the same parts indicate non-significant difference at $P<0.05$ (Tukey-Kramer's test). Error bars indicate SE $(\mathrm{n}=3)$.

Table 3. Characteristics of the number of internodes $(N I)$ and Probability of axillary bud presence $(P A)$, and cultivar lateral branch characteristics.

\begin{tabular}{|c|c|c|c|c|c|c|c|c|c|c|c|c|c|c|}
\hline \multirow{3}{*}{$\begin{array}{l}\text { Cultivar } \\
\text { Madoka }\end{array}$} & \multirow{2}{*}{\multicolumn{2}{|c|}{$N I$}} & \multirow{2}{*}{\multicolumn{2}{|c|}{$P A(\%)$}} & \multicolumn{10}{|c|}{ Characteristics of lateral branches } \\
\hline & & & & & \multicolumn{2}{|c|}{$\begin{array}{l}\text { Fresh weight } \\
\qquad(W B)(\mathrm{g})\end{array}$} & \multicolumn{2}{|l|}{$\begin{array}{l}\text { Leaf area } \\
\quad\left(\mathrm{cm}^{2}\right)\end{array}$} & \multicolumn{2}{|c|}{$\begin{array}{l}\text { Thickness } \\
(\mathrm{mm})\end{array}$} & \multicolumn{2}{|l|}{$\begin{array}{l}\text { Length } \\
(\mathrm{mm})\end{array}$} & \multicolumn{2}{|c|}{$\begin{array}{l}\text { Diameter of } \\
\text { lateral head } \\
\quad(\mathrm{mm})\end{array}$} \\
\hline & $22.0 \pm 0.5^{z}$ & $\mathrm{a}^{\mathrm{y}}$ & $0 \pm 0$ & $\mathrm{~d}$ & - & - & - & - & - & - & - & - & - & - \\
\hline Grandome $\mathrm{e}^{\mathrm{x}}$ & $21.2 \pm 0.5$ & $\mathrm{a}$ & $<1.8 \pm 0.7$ & $\mathrm{~d}$ & $140.4 \pm 55.7$ & - & $1196.0 \pm 408.7$ & - & $10.5 \pm 1.9$ & - & $132.5 \pm 17.1$ & - & - & - \\
\hline Yumehibiki & $16.8 \pm 0.1$ & $\mathrm{~b}$ & $23.4 \pm 2.8$ & $\mathrm{c}$ & $48.0 \pm 8.6$ & $\mathrm{~b}$ & $437.6 \pm 79.1$ & $\mathrm{~b}$ & $12.2 \pm 0.4$ & $\mathrm{a}$ & $82.0 \pm 6.1$ & $\mathrm{~b}$ & $13.7 \pm 1.6$ & $\mathrm{c}$ \\
\hline Pixel & $15.4 \pm 0.6$ & $\mathrm{~b}$ & $50.1 \pm 1.6$ & $\mathrm{~b}$ & $57.1 \pm 3.6$ & $\mathrm{~b}$ & $466.4 \pm 29.0$ & $\mathrm{~b}$ & $12.2 \pm 0.3$ & $\mathrm{a}$ & $129.7 \pm 3.9$ & a & $29.1 \pm 2.0$ & $\mathrm{a}$ \\
\hline Speed dome & $15.8 \pm 0.3$ & $\mathrm{~b}$ & $55.6 \pm 3.4$ & $\mathrm{~b}$ & $58.4 \pm 5.2$ & $\mathrm{~b}$ & $476.9 \pm 46.9$ & $\mathrm{~b}$ & $12.6 \pm 0.3$ & $\mathrm{a}$ & $105.3 \pm 3.7$ & $\mathrm{~b}$ & $22.6 \pm 1.4$ & $\mathrm{~b}$ \\
\hline Ryokurei & $17.0 \pm 0.3$ & $\mathrm{~b}$ & $85.3 \pm 2.2$ & a & $87.3 \pm 8.3$ & $\mathrm{a}$ & $756.3 \pm 70.9$ & $\mathrm{a}$ & $10.4 \pm 0.2$ & $\mathrm{~b}$ & $139.7 \pm 5.3$ & $\mathrm{a}$ & $12.5 \pm 1.1$ & $\mathrm{c}$ \\
\hline
\end{tabular}

${ }^{\mathrm{z}}$ Mean value $\pm \mathrm{SE}$ of three replicates.

y The same letter within a column indicates non-significant difference at $P<0.05$ (Tukey-Kramer's test). Tukey-Kramer's test of probability of axillary bud presence was conducted after inverse sine transformation.

x It was undetermined if lateral branches of 'Grandome' were axillary or adventitious buds. In addition, the number of branches of 'Grandome' sampled was small with large variance. Therefore, the data set representing the lateral branch characteristics of 'Grandome' is only a reference and was excluded from the Tukey-Kramer's test. 
Table 4. Explanatory variables $\left(\beta_{0}, \beta_{1}\right.$, and $\left.\beta_{2}\right)$, Akaike's information criteria (AIC), and coefficients of determination $\left(R^{2}\right)$ of equations used to estimate the relationship between the fresh weight of apical heads $(A)$ and stalk diameter $(S)$ in a generalized linear model approach.

\begin{tabular}{cccccc}
\hline \hline \multirow{2}{*}{ Equation } & \multicolumn{3}{c}{ Explanatory variable } & \multirow{2}{*}{ AIC } & \multirow{2}{*}{$R^{2}$} \\
\cline { 2 - 4 } & $\beta_{0}$ & $\beta_{1}$ & $\beta_{2}$ & & 162.91 \\
\multirow{2}{*}{$\# 1: A=\exp \left(\beta_{0}+\beta_{1} S+\beta_{2} S^{2}\right)$} & $5.25^{* * * z}$ & $-0.00855^{\mathrm{NS}}$ & $0.000628^{\mathrm{NS}}$ & & 0.94 \\
$\# 2: A=\exp \left(\beta_{0}+\beta_{1} S\right)$ & $4.21^{* * *}$ & $0.0429^{* * *}$ & - & 162.19 & 0.94 \\
$\# 3: A=\exp \left(\beta_{0}+\beta_{2} S^{2}\right)$ & $5.07^{* * *}$ & - & $0.000524^{* * *}$ & 160.95 & 0.95 \\
\hline
\end{tabular}

z ***, **, and * indicate the statistical significance at $P<0.001, P<0.01$, and $P<0.05$, respectively, and NS indicates the non-significance of the explanatory variable parameter.

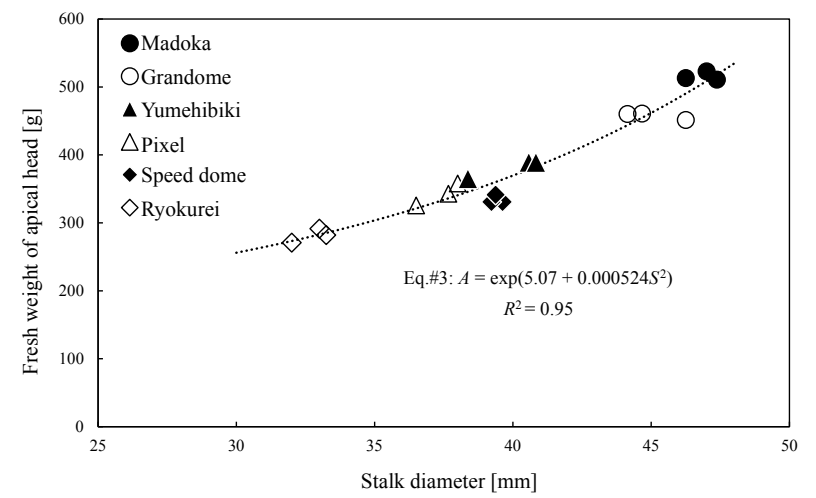

Fig. 4. Regression curve of Eq. \#3 between fresh weights of the apical heads and stalk diameters. $A$ and $S$ in the equation indicate fresh weights of apical heads and stalk diameters, respectively.

Comparison of lateral branches among cultivars (Exp. 3)

The NI of 'Madoka' and 'Grandome' ranged from 21.2-22.0, which was significantly higher than that of the other four cultivars, at 15.4-17.0 (Table 3). The $P A$ varied significantly depending on the cultivar. The $P A$ of 'Madoka' was $0 \%$ (Table 3). Although it was undetermined if lateral branches of 'Grandome' were axillary or adventitious buds, the $P A$ of 'Grandome' was less than $1.8 \%$. The $P A$ of 'Yumehibiki', 'Pixel', 'Speed dome', and 'Ryokurei' were $23.4 \%, 50.1 \%, 55.6 \%$, and $85.3 \%$, respectively. The lateral branches of 'Ryokurei' had distinctive features. For example, $W B$ and LA were significantly larger but the thickness was significantly thinner than that of any other cultivar (Table 3). The branches of 'Pixel' and 'Ryokurei' were significantly longer than those of other cultivars (Table 3). The largest lateral head diameter was observed in 'Pixel', followed by 'Speed dome'; 'Yumehibiki' and 'Rykurei' had the smallest diameters (Table 3).

\section{Analysis of the relationship between apical head weight and stalk diameter}

Regression analysis between $A$ and $S$ was conducted using the data from all the plots of the six cultivars included in Exp. 1 by GLM, considering the three candidate equations \#1, \#2, and \#3 (Table 4). We confirmed Eq. \#3 to be the best model because all the explanatory variables were significantly different from zero, and the equation showed the lowest AIC value (Table 4; Fig. 4). The coefficient of determination $\left(R^{2}\right)$ of Eq. \#3 was also higher than that of any of the other equations.

\section{Discussion}

Biomass allocation between the main shoot and lateral branches (Exp. 1, 2)

Although various comparisons were conducted based on FW in this study, it is possible to discuss the biomass allocation to each part of the broccoli shoot because there was no significant difference in dry matter concentration among parts and cultivars (Table S1). As biomass allocation and bud outgrowth are strongly affected by environmental conditions (Dun et al., 2006; McConnaughay and Coleman, 1999), the proportions of certain parts of certain cultivars were not constant. Furthermore, the breakdown of shoots of the same cultivar were different between Exp. 1 and 2, which is in agreement with previous studies showing that the proportion of lateral branches decreases with an increase in planting density (Chung, 1982; Cutcliffe, 1975). However, since the branching habit of cultivars showed the same tendency in Exp. 1 and 2, it is possible to consider the biomass allocation to lateral branches based on these experiments.

Based on a comparison of the proportion of each part among six cultivars, it was revealed that the proportion of the main shoot (apical head and leaves on the main stem) decreased with increases in that of the lateral branches (Fig. 2a). If photoassimilates are always distributed to the main shoot as a priority, and only the amount of photoassimilates exceeding the sink limitation of the main shoot are used for the development of other parts, the whole shoot weight would decrease by just the weight of the part removed and the weight of the main shoot would remain constant (Barbier et al., 2015; Egli and Bruening, 2001; Reynolds et al., 2005). However, the FW of the whole shoot did not significantly change despite nipping the branches, while the FW of the main shoot increased in Exp. 2 (Fig. 3). In addition, this tendency was marked when the proportion of lateral branches was high, as in the case of 'Ryokurei'. This means that the total quantity of photoassimilates that a broccoli plant can produce for a certain period is almost constant regardless of the bud outgrowth and proportion of total photoassimilates dis- 
tributed to lateral branches. Therefore, we quantitatively demonstrated a competitive relationship between apical head development and lateral bud outgrowth, which was already empirically known (Bouquet, 1950; Le Strange et al., 1996). Pornsuriya and Teeraskulchon (1997) reported that nipping all the lateral buds tended to produce the highest yield. Although the reason for the increasing yield was not mentioned, it is probable that the FW of apical heads increased, and this is consistent with our result.

From the perspective of light interception, plant growth and LA are closely related (Charles-Edwards, 1982; Francescangeli et al., 2006). In accordance with former studies, the FW of the whole shoot tended to be high in cultivars with high $\mathrm{LA}_{\mathrm{W}}$ in this study (Fig. 2a, b; Table 2). However, the FW of apical heads was not correlated with $\mathrm{LA}_{\mathrm{W}}$, but was positively correlated with $\mathrm{LA}_{\mathrm{M}}$ and negatively with $\mathrm{LA}_{\mathrm{B}}$ (Table 2). Furthermore, the FW of lateral branches showed an inverse relationship with that of the apical heads (Table 2). These results imply that the leaves on the main stem supply photoassimilates mainly to the main shoot, while those on branches supply to branches. Further studies are needed to elucidate the role of light interception, although it is likely that the main shoot competes with branches for light interception; in other words, the main shoot fails to receive as much light as the branches do, which correlates with the proportion of total photoassimilates distributed to the branches.

\section{Pattern of branch generation and branch characteris- tics (Exp. 3)}

Even though all six cultivars used in this study were classified as heading type broccoli, the number of lateral branches was significantly different among them (Fig. 2a). It is possible to express the number of lateral branches on a plant as the product of $N I$ and $P A(N I \times$ $P A$ ), and the FW of lateral branches on a plant as the product of $N I, P A$, and $W B(N I \times P A \times W B)$. Contrary to our expectation that these three factors individually differ according to cultivars, only $P A$ varied across a wide range $(P A=0-85 \%)$ in this study. There were only two grades of $N I: N I=21-22$ ('Madoka' and 'Grandome') and $N I=15-17$ (the other four cultivars), and two grades of $W B: W B=87 \mathrm{~g}$ ('Ryokurei') and $W B=48$ $58 \mathrm{~g}$ (the other three cultivars). This indicated that $P A$ is likely to be the determining factor of the branching habit among cultivars, but further research comparing numerous cultivars is necessary to confirm its importance.

Additionally, the characteristics of lateral branches were different among cultivars. Particularly, the branches of 'Ryokurei' were distinctive. While its FW and LA per bud were significantly higher than those of the other cultivars (Table 3 ), it had the longest and thinnest lateral branches, reflecting its slender shape. Stalk diameters of 'Ryokurei' apical heads were also the smallest among the cultivars (Fig. 4); therefore, such a main shoot characteristic may be reflected in lateral shoots as a genetic trait of this cultivar. It is assumed that the yield of 'Ryokurei' was not very high because of the low FW of the apical head. However, the high branching habit is suitable for harvesting both apical and lateral heads (Bouquet, 1950; Singh et al., 2011; Stephens, 1994; Yoldas et al., 2008). 'Madoka' clearly produced the largest apical heads (Table 1), but lateral heads cannot be expected at all because it does not produce any branches. As 'Ryokurei' showed the same FW level of whole shoots as 'Madoka' (Fig. 2a), their total yields, including lateral heads, may be comparable. Therefore, it is quite important to understand the branching habits and select an appropriate cultivar in accordance with cultivation objectives.

Analysis of the relationship between apical head weight and stalk diameter

Francescangeli et al. (2006) suggested that differences in the stalks affect the change in FW of apical heads based on the planting density because the head diameter, floret number, and weight did not change. This was evidenced by the strong relationship between $A$ and $S$ in this study (Table 4; Fig. 4). It was possible to select a regression curve (Eq. \#1) or a line (Eq. \#2) as in typical regression analysis due to the high $R^{2}$ value; however, we found a more suitable curve (Eq.\#3) by GLM. An apical head can be divided into two parts, the flower bud (florets) dome, and stalk. Although the shapes of the domes were slightly different depending on the cultivar (Fig. 1), the influence on the FW seemed limited because every head was harvested uniformly with the same dome diameter $(12 \mathrm{~cm})$. On the contrary, stalk thicknesses were not uniform. As the stalk can be regarded as a column of standard length $(15 \mathrm{~cm})$, its weight should be proportional to the cross-sectional area, i.e., the square of the stalk (semi) diameter. Hence, Eq. \#3, which explains the FW of apical heads using the square of stalk diameters, appears reasonable (Table 4).

In Exp. 2, the average FW values $( \pm \mathrm{SE}, \mathrm{n}=3)$ of the apical heads and stalk diameters of 'Ryokurei' in the control plots were $315.7 \pm 16.7 \mathrm{~g}$ and $35.9 \pm 0.6 \mathrm{~mm}$, respectively. They increased to $394.8 \pm 11.8 \mathrm{~g}$ and 42.2 $\pm 0.5 \mathrm{~mm}$, respectively, in the nipping plots. When stalk diameters are $35.9 \mathrm{~mm}$ (control plot) and $42.2 \mathrm{~mm}$ (nipping plot), Eq. \#3 estimates the FW of apical heads as $314.0 \mathrm{~g}$ and $406.4 \mathrm{~g}$, respectively, showing that the means estimated by Eq. \#3 for the FW of apical heads are accurate with relative errors of less than $3 \%$ $([315.7-314.0] / 314.0=0.54 \% ;[394.8-406.4] / 406.4$ $=-2.9 \%$ ). Therefore, Eq. $\# 3$ is the best equation derived from different cultivars to explain the relationship between the FW of apical heads and stalk diameters. It may also be applicable to explain the changes in the FW of apical heads and stalk diameter caused by different cultivation conditions in the same cultivar. 
Because of the multidimensional approach used to evaluate the lateral branches of broccoli, we could elucidate the proportion of lateral branches, the competitive relationship between the main shoot and lateral branches, plasticity of head size based on the presence of lateral branches, differences in branch characteristics (generation pattern and shape) among cultivars, and the correlation between the apical head weight and stalk diameter. Based on these findings, it is clearly suggested that using a cultivar with a weaker branching habit or suppressing lateral bud outgrowth by taking some countermeasures would be effective to increase the yield when aiming to harvest a single apical head. In the methods we have reported before to harvest two large heads (Takahashi et al., 2018a, 2019), in which we recommended nipping extra branches, the effect of nipping extra branches is also supported by the logic of avoiding biomass competition among branches. Therefore, the findings in this study will contribute to increase knowledge regarding these diverse methods and improve the stable production of broccoli.

\section{Acknowledgements}

We thank Mr. Kuriyama, Ms. Tsutsui, Mr. Sakamoto, and Ms. Onishi of the Institute of Vegetable and Floriculture Science, NARO, for growing the plants and supporting the experiments.

\section{Literature Cited}

Adjei-Frimpong, P., J. Ofosu-Anim and J. C. Norman. 2011. Disbudding effects on growth analysis of Celosia (Celosia cristata). Adv. Hortic. Sci. 25: 223-231.

Barbier, F. F., J. E. Lunn and C. A. Beveridge. 2015. Ready, steady, go! A sugar hit starts the race to shoot branching. Curr. Opin. Plant Biol. 25: 39-45.

Bazzaz, F. A., N. R. Chiariello, P. D. Coley and L. F. Pitelka. 1987. Allocating resources to reproduction and defense. BioScience 37: 58-67.

Beveridge, C. A., J. L. Weller, S. R. Singer and J. M. I. Hofer. 2003. Axillary meristem development. Budding relationships between networks controlling flowering, branching, and photoperiod responsiveness. Plant Physiol. 131: 927934.

Bouquet, A. G. B. 1950. Sprouting broccoli. Or. Agr. Exp. Sta. Bull. 704 .

Charles-Edwards, D. A. 1982. Physiological determinants of crop growth. Academic Press, Sydney.

Chung, B. 1982. Effects of plant density on the maturity and once-over harvest yields of broccoli. J. Hortic. Sci. 57: 365372.

Cline, M. G. 1991. Apical dominance. Bot. Rev. 57: 318-358.

Cockshull, K. E. 1982. Disbudding and its effect on dry matter distribution in Chrysanthemum morifolium. J. Hortic. Sci. 57: 205-207.

Crawley, M. J. 2005. Statistics: an introduction using R, 2005. Wiley, Hoboken, NJ.

Cutcliffe, J. A. 1975. Effect of plant spacing on single-harvest yields of several broccoli cultivars. HortScience 10: 417 419.

De Swart, E. A. M., L. F. M. Marcelis and R. E. Voorrips. 2006. Variation in relative growth rate and growth traits in wild and cultivated capsicum accessions grown under different temperatures. J. Hortic. Sci. Biotech. 81: 1029-1037.

Duggan, B. L., R. A. Richards and A. F. Van Herwaarden. 2005a. Agronomic evaluation of a tiller inhibition gene (tin) in wheat. II. Growth and partitioning of assimilate. Aust. J. Agr. Res. 56: 179-186.

Duggan, B. L., R. A. Richards, A. F. Van Herwaarden and N. A. Fettell. 2005b. Agronomic evaluation of a tiller inhibition gene (tin) in wheat. I. Effect on yield, yield components, and grain protein. Aust. J. Agr. Res. 56: 169-178.

Dun, E. A., B. J. Ferguson and C. A. Beveridge. 2006. Apical dominance and shoot branching. Divergent opinions or divergent mechanisms? Plant Physiol. 142: 812-819.

Egli, D. B. and W. P. Bruening. 2001. Source-sink relationships, seed sucrose levels and seed growth rates in soybean. Ann. Bot. 88: 235-242.

Erdem, T., L. Arin, Y. Erdem, S. Polat, M. Deveci, H. Okursoy and H. T. Gültaş. 2010. Yield and quality response of drip irrigated broccoli (Brassica oleracea L. var. italica) under different irrigation regimes, nitrogen applications and cultivation periods. Agr. Water Manage. 97: 681-688.

Francescangeli, N., M. A. Sangiacomo and H. Martí. 2006. Effects of plant density in broccoli on yield and radiation use efficiency. Sci. Hortic. 110: 135-143.

Georgiev, H. 1991. Heterosis in Tomato Breeding. p. 83-98. In: Kalloo G. (ed.). Genetic Improvement of Tomato. Springer, Berlin.

Horvath, D. P., J. V. Anderson, W. S. Chao and M. E. Foley. 2003. Knowing when to grow: signals regulating bud dormancy. Trends Plant Sci. 8: 534-540.

Jett, L. W., R. D. Morse and C. R. O'Dell. 1995. Plant density effects on single-head broccoli production. HortScience 30: $50-52$.

Kahn, B. A., P. G. Shilling, G. H. Brusewitz and R. W. McNew. 1991. Force to shear the stalk, stalk diameter, and yield of broccoli in response to nitrogen fertilization and within-row spacing. J. Am. Soc. Hortic. Sci. 116: 222-227.

Kodera, T. 1988. Studies on two large curds harvesting technique by means of pinching in broccoli. Bull. Tokyo Agr. Exp. Sta. 21: 1-14 (In Japanese with English abstract).

Lafarge, T. A. and G. L. Hammer. 2002. Predicting plant leaf area production: shoot assimilate accumulation and partitioning, and leaf area ratio, are stable for a wide range of sorghum population densities. Field Crops Res. 77: 137-151.

Le Strange, M. E., M. Cahn, S. Koike and R. Smith. 1996. Broccoli Production in California. UCANR Publications.

Luo, L., M. Takahashi, H. Kameoka, R. Qin, T. Shiga, Y. Kanno, M. Seo, M. Itoh, G. Xu and J. Kyozuka. 2019. Developmental analysis of the early steps in strigolactone-mediated axillary bud dormancy in rice. Plant J. 97: 1006-1021.

Maghfoer, M. D., R. Soelistyono and N. Herlina. 2015. Growth and yield of eggplant (Solanum melongena L.) on various combinations of $\mathrm{N}$-source and number of main branch. AGRIVITA 36: 285-294.

Martin, C. A. and R. G. Sideman. 2012. Survival and yields of fall-planted winter sprouting broccoli grown in high tunnels for spring harvest in the Northeastern United States. HortTechnology 22: 345-352.

McCarthy, M. C. and B. J. Enquist. 2007. Consistency between an allometric approach and optimal partitioning theory in global patterns of plant biomass allocation. Funct. Ecol. 21: 713-720.

McConnaughay, K. D. M. and J. S. Coleman. 1999. Biomass allocation in plants: Ontogeny or optimality? A test along three resource gradients. Ecol. 80: 2581-2593. 
Poorter, H. and O. Nagel. 2000. The role of biomass allocation in the growth response of plants to different levels of light, $\mathrm{CO} 2$, nutrients and water: a quantitative review. Funct. Plant Biol. 27: 1191-1191.

Pornsuriya, P. and S. Teeraskulchon. 1997. Studies on broccoli production in Chonburi Province, Thailand. Kasetsart J. Nat. Sci. 32: 81-85.

Reilly, K., J. Valverde, L. Finn, D. K. Rai, N. Brunton, J. C. Sorensen, H. Sorensen and M. Gaffney. 2014. Potential of cultivar and crop management to affect phytochemical content in winter-grown sprouting broccoli (Brassica oleracea L. var. italica). J. Sci. Food Agr. 94: 322-330.

Reynolds, M. P., A. Pellegrineschi and B. Skovmand. 2005. Sink -limitation to yield and biomass: a summary of some investigations in spring wheat. Ann. Appl. Biol. 146: 39-49.

Sato, Y. 2015. Study on techniques for increasing yield by two times harvests from one-stock on broccoli. Bull. Tokushima Agr. Forest. Fish. Tech. Sup. Ctr: 13-19 (In Japanese).

Schellenberg, D. L., A. D. Bratsch and Z. Shen. 2009. Large single-head broccoli yield as affected by plant density, nitrogen, and cultivar in a plasticulture system. HortTechnology 19: 792-795.

Schnier, H. F., M. Dingkuhn, S. K. De Datta, K. Mengel and J. E. Faronilo. 1990. Nitrogen fertilization of direct-seeded flooded vs. transplanted rice: I. Nitrogen uptake, photosynthesis, growth, and yield. Crop Sci. 30: 1276-1284.
Singh, M., D. K. Rana, J. M. S. Rawat and S. S. Rawat. 2011. Effect of $\mathrm{GA}_{3}$ and kinetin on growth, yield and quality of sprouting broccoli (Brassica oleracea var. italica). J. Hortic. Forest. 3: 282-285.

Stephens, J. M. 1994. Broccoli-brassica oleracea L. (Italica Group) University of Florida Cooperative Extension Service, Institute of Food and Agriculture Sciences, EDIS.

Takahashi, M., Y. Nakano and H. Sasaki. 2018a. Increasing the yield of broccoli (Brassica oleracea L. var. italica) cultivar 'Yumehibiki' during the off-crop season by limiting the number of lateral branches. Hort. J. 87: 508-515.

Takahashi, M., Y. Yanai, H. Umeda and H. Sasaki. 2018b. Relationship between growth and $\mathrm{N}$ : P of cabbage (Brassica oleracea L., var. capitata) plug seedlings according to moisture content and nitrogen and phosphorus application after transplanting. Sci. Hortic. 233: 294-301.

Takahashi, M., T. Ohara, F. Sato, Y. Nakano and H. Sasaki. 2019. Harvesting two heads from one stock of broccoli (Brassica oleracea L. var. italica) 'Yumehibiki' by pinching the shoot apical bud in autumn cropping. Hort. J. 88: 364-372.

Tremblay, N. 1989. Effect of nitrogen sources and rates on yield and hollow stem development in broccoli. Can. J. Plant Sci. 69: 1049-1053.

Yoldas, F., S. Ceylan, B. Yagmur and N. Mordogan. 2008. Effects of nitrogen fertilizer on yield quality and nutrient content in broccoli. J. Plant Nutr. 31: 1333-1343. 